\title{
Monoclonal Antibody against the Platelet Glycoprotein (GP) IIb/IIla Receptor Prevents Coronary Artery Reocclusion after Reperfusion with Recombinant Tissue-type Plasminogen Activator in Dogs
}

\author{
Tsunehiro Yasuda, Herman K. Gold, John T. Fallon, Robert C. Leinbach, J. Luis Guerrero, Lesley E. Scudder, \\ Machito Kanke, David Shealy, Michael J. Ross, Desire Collen, and Barry S. Coller \\ Cardiac Division and the Departments of Medicine and Pathology, Massachusetts General Hospital and Harvard Medical School, \\ Boston, Massachusetts 02114; the Division of Hematology, State University of New York at Stony Brook, New York 11794; the \\ Departments of Biochemistry and Medicine, University of Vermont College of Medicine, Burlington, Vermont 05402; Centocor, Inc., \\ Malvern, Pennsylvania 19355; and Genentech, Inc., South San Francisco, California 94080
}

\section{Abstract}

Localized thrombosis was produced in the left anterior descending (LAD) coronary artery of open chest dogs by constricting a segment so as to produce $>\mathbf{9 0 \%}$ stenosis (reducing blood flow to $40 \pm 10 \%$ of baseline), and placing a thrombus in the segment immediately proximal to the stenosis by inducing endothelial cell injury and instilling a mixture of blood and thrombin.

Intravenous infusion of recombinant tissue-type plasminogen activator (rt-PA) at a rate of $15-30 \mu \mathrm{g} / \mathrm{kg}$ per min for 30 or $60 \mathrm{~min}$ in eight dogs induced coronary artery reperfusion within $23 \pm 7$ min (mean $\pm S D$ ), but reocclusion occurred despite heparin anticoagulation in all but one of these dogs within $7 \pm 5$ min.

Intravenous injection of $0.8 \mathrm{mg} / \mathrm{kg}$ of the $\mathrm{F}\left(\mathrm{ab}^{\prime}\right)_{2}$ fragment of a monoclonal antibody (7E3) directed against the platelet GPIIb/IIIa receptor, prevented reocclusion in 10/10 dogs during an observation period of $2 \mathrm{~h}(P<0.001$ vs. rt-PA alone). The antibody abolished ADP-induced platelet aggregation and markedly prolonged the bleeding time. Intravenous aspirin or dipyridamole prevented reocclusion for $1 \mathrm{~h}$ or more in only 2/7 and 1/6 dogs, respectively.

We conclude that the monoclonal antibody is very effective in preventing reocclusion after successful thrombolysis of occluded coronary arteries with rt-PA.

\section{Introduction}

Reocclusion is a common complication after coronary artery reperfusion with thrombolytic agents, occurring in $\sim 25 \%$ of the patients (1-3). The main determinant for reocclusion is the extent of the residual stenosis after thrombolysis $(2,3)$; thus, with recombinant tissue-type plasminogen activator (rt-PA), ${ }^{1}$ the majority of patients with a stenosis of $>80 \%$ develop reocclusion unless treated with a maintenance infusion (2).

Address reprint requests to Dr. Gold, Cardiac Unit, ACC3A, Suite 380, Massachusetts General Hospital, Boston, MA 02114.

Received for publication 10 June 1987 and in revised form 1 September 1987.

1. Abbreviations used in this paper: GP, glycoprotein; rt-PA, recombinant tissue-type plasminogen activator.

J. Clin. Invest.

(C) The American Society for Clinical Investigation, Inc. 0021-9738/88/04/1284/08 $\$ 2.00$

Volume 81, April 1988, 1284-1291
Fixed atheromatous disease is responsible for much of the residual stenosis after thrombolysis, and reocclusion occurs by the superimposition of thrombi containing both platelets and fibrin (4). Recently, one of us described a murine monoclonal antibody (7E3) that binds to the platelet glycoprotein GPIIb/ IIIa receptor and blocks platelet aggregation induced by a variety of physiological agonists (5). Intravenous infusion of $\mathrm{F}\left(\mathrm{ab}^{\prime}\right)_{2}$ fragments of the antibody at a dose of $0.8 \mathrm{mg} / \mathrm{kg}$ in dogs and monkeys induced profound inhibition of platelet aggregation ex vivo and platelet thrombus formation in vivo, without producing severe thrombocytopenia or spontaneous bleeding $(6,7)$.

In the present study we evaluated the efficacy of $F\left(a b^{\prime}\right)_{2}$ fragments of 7E3 for the prevention of coronary artery reocclusion after thrombolysis with rt-PA in a dog model consisting of a coronary artery thrombus placed adjacent to a fixed high grade (>90\%) stenosis in a vessel segment with damaged endothelium. ${ }^{2}$ In this model, coronary thrombi can be lysed readily by intravenous rt-PA, but the thrombogenic stimulus is of such magnitude that reocclusion occurs rapidly and consistently when the experimental animals are treated with heparin alone or heparin in combination with either aspirin or dipyridamole. $^{2}$

\section{Methods}

Reagents. rt-PA was supplied by Genentech, Inc., South San Francisco, CA. Two preparations were used: one, G11021, is produced in roller bottles and consists predominantly of two-chain rt-PA; the other, G11035, is produced in suspension culture and consists predominantly of single chain rt-PA. The production of the monoclonal antibody 7E3, its purification, and fragmentation into $F\left(a b^{\prime}\right)_{2}$ fragments with pepsin have been described in detail $(6,7)$. Antibody given to the last five dogs was prepared by a modified technique involving fragmentation with $120 \mathrm{U}$ of pepsin (Cooper Biomedical, Malvern, PA) per mg 7E3 at pH $4.2\left(0.15 \mathrm{M} \mathrm{NaCl}, 0.1 \mathrm{M} \mathrm{Na}\right.$ citrate) for $6 \mathrm{~h}$ at $37^{\circ} \mathrm{C}$. The digestion was stopped by raising the $\mathrm{pH}$ to 7.5 with $1 \mathrm{M}$ Tris $\cdot \mathrm{HCl}, 0.02 \mathrm{M}$ EDTA, pH 8.0, and the $F\left(a b^{\prime}\right)_{2}$ fragments were purified by gel filtration on Superose 12 (Pharmacia Fine Chemicals, Piscataway, NJ) equilibrated with $0.15 \mathrm{M} \mathrm{NaCl}$, and chromatography on Q-Sepharose Fast Flow (Pharmacia) with elution by a linear gradient from 0 to $1.0 \mathrm{M} \mathrm{NaCl}$ in $0.05 \mathrm{M}$ Tris $\cdot \mathrm{HCl}, \mathrm{pH}$ 8.0. The final material was pooled and then both concentrated and diafiltered with $0.15 \mathrm{M} \mathrm{NaCl}$ using a YM-10 filter (Amicon Corp., Waltham, MA). Antibody fragments were prepared at concentrations ranging from 0.68 to $3.1 \mathrm{mg} / \mathrm{ml}$ in $0.15 \mathrm{M} \mathrm{NaCl}$ and frozen until just before use. When analyzed for endotoxin with an

2. Yasuda, T., H. K. Gold, J. T. Fallon, R. C. Leinbach, H. D. Garabedian, L. Guerrero, and D. Collen. Manuscript submitted for publication. 
amebocyte lysate clotting assay (Pyrogent; Mallinckrodt, St. Louis, MO) the first antibody preparations were found to contain between 2 and $>80$ endotoxin $\mathrm{U} / \mathrm{mg}$ protein. The preparations for the last five dogs had lower endotoxin values of $0.5-1$ endotoxin $U / \mathrm{mg}$ as judged by a spectrophotometric assay (Whittaker M. A. Bioproducts, Walkersville, $\mathrm{MD})$. A control $\mathrm{F}\left(\mathrm{ab}^{\prime}\right)_{2}$ fragment of a monoclonal antibody directed against an ovarian carcinoma antigen (OC-125) (Centocor, Malvern, PA) (8) was prepared as described above with only minor modifications.

Animal model. Coronary artery thrombosis and endothelial cell damage was produced in dogs as described before (9). In addition, superimposed high grade stenosis was produced by the application of an external constrictor, and blood flow was continuously monitored with an electromagnetic flow probe. Mongrel dogs weighing $\sim 20-25$ $\mathrm{kg}$ were anesthetized with a slow intravenous injection of sodium pentobarbital, intubated and placed on an artificial ventilator. A left thoracotomy was performed in the 5th-6th intercostal space, and an arterial catheter was placed in the internal mammary artery for blood pressure monitoring. Procainamide ( $1.5 \mathrm{~g}$ i.m. in two to three sites) was then given, the pericardium opened, and a pericardial cradle prepared. The left anterior descending coronary artery was dissected out from the epicardium, side branches were ligated and a $2.5-\mathrm{cm}$ segment isolated. An electromagnetic flow probe (FM 501; Carolina Medical Electronics, King, NC) was placed on the most proximal portion of the segment and intravenous lidocaine (15-mg bolus followed by a constant infusion at $1 \mathrm{mg} / \mathrm{min}$ ) was infused. A control left coronary angiogram was performed by injecting $\sim 2 \mathrm{ml}$ of Renograffin 76 by hand through a modified Judkin's 7 French catheter inserted from a carotid artery. One $\mathrm{ml}$ of blood was then removed and kept in a syringe for later use in forming the thrombus, and heparin (5,000 $\mathrm{U}$ intravenous bolus) was administered. Additional 1,000 $\mathrm{U}$ boluses of heparin were administered at hourly intervals. A permanent 2-mm wide constrictor was placed near the distal end of the segment and adjusted so as to reduce coronary artery blood flow to $\sim 40 \pm 10 \%$ of control. High resolution postmortem angiograms in selected animals showed that a constriction so placed decreased the luminal diameter by $>90 \%$. The 1 $\mathrm{cm}$ of coronary artery just proximal to the constriction was then emptied of blood and isolated between temporary silk snares. Intimal damage was induced by grasping the segment with forceps and then the segment was flushed by releasing the proximal snare and injecting saline retrograde through a cannulated side branch. The segment was then reisolated and $0.1 \mathrm{ml}$ of thrombin (topical thrombin, $1000 \mathrm{U} / \mathrm{ml}$; Parke-Davis Co., Morris Plains, NJ) and $0.3 \mathrm{ml}$ of the stored blood were injected into the isolated segment. After $\sim 5 \mathrm{~min}$, first the proximal and then the distal ties were released and the side branch catheter was removed, whereas the permanent constrictor remained in place. Approximately $30 \mathrm{~min}$ after injecting the thrombin and blood, a repeat angiogram was performed to confirm the persistence of complete coronary artery occlusion as demonstrated by continuous electromagnetic flow probe monitoring.

The rt-PA infusion was then started in the animals not receiving antiplatelet agents. The other animals were given the $F\left(a b^{\prime}\right)_{2}$ fragment of $7 \mathrm{E} 3(0.7-0.8 \mathrm{mg} / \mathrm{kg}$ in $10 \mathrm{dogs})$, acetylsalicylic acid $(35 \mathrm{mg} / \mathrm{kg}$ in three dogs), dipyridamole $(0.6 \mathrm{mg} / \mathrm{kg}$ in six dogs $)$, or fragments of the control monoclonal antibody OC- $125(0.7-0.8 \mathrm{mg} / \mathrm{kg}$ in two dogs) by slow intravenous injection. Approximately $10 \mathrm{~min}$ later, the latter animals received an infusion of $\mathrm{rt}-\mathrm{PA}$ at $15 \mu \mathrm{g} / \mathrm{kg}$ per min for the predominantly two chain form (G11021), or at $30 \mu \mathrm{g} / \mathrm{kg}$ per min for the predominantly single chain form (G1 1035) for $30 \mathrm{~min}$. In animals that did not achieve at least partial coronary artery reperfusion near the end of the $30 \mathrm{~min}$ infusion, rt-PA infusion was continued for another $30 \mathrm{~min}$. In addition, in four dogs, acetylsalicylic acid $(35 \mathrm{mg} / \mathrm{kg})$ was injected intravenously at the time of reperfusion. The blood flow in the vessel was monitored continuously and when flow appeared to be restored, another angiogram was immediately performed. The reperfusion time was taken as the number of minutes from the beginning of the rt-PA infusion until reperfusion was documented by the flow meter and confirmed by the repeat angiogram showing complete antegrade filling of the artery with rapid clearance of the dye (in less than four cardiac cycles). After reperfusion was obtained, blood flow was monitored for evidence of reocclusion, with the final confirmation again obtained by angiography using the same criteria as were used for establishing reperfusion. The reocclusion time was taken as the interval between documented reperfusion and reocclusion.

Blood analyses. Bleeding times were performed before and $30 \mathrm{~min}$ after injections of the $\mathrm{F}\left(\mathrm{ab}^{\prime}\right)_{2}$ fragment of 7E3 (eight dogs), control antibody OC-125 (two dogs) or aspirin (three dogs), with a springloaded blade device (Simplate; General Diagnostic Corp., Morris Plains, NJ, or Surgicutt; International Technidyne Corp, Edison, NJ), applied to a shaved foreleg. Venous blood samples for determination of the levels of fibrinogen, activated partial thromboplastin time, ADPinduced platelet aggregation and ${ }^{125} \mathrm{I}-7 \mathrm{E} 3$ binding were collected into $0.01 \mathrm{M}$ citrate containing $150 \mathrm{KIU} / \mathrm{ml}$ aprotinin (Sigma Chemical Co., St. Louis, MO). Platelet counts were performed with an automated particle counter (Coulter, Hialeah, FL) on blood drawn into EDTA. Platelet-rich plasma was prepared as previously described for the aggregation and ${ }^{125} \mathrm{I}-7 \mathrm{E} 3$ binding studies (6). The number of $\mathrm{F}\left(\mathrm{ab}^{\prime}\right)_{2}$ molecules bound per platelet in vivo was estimated from the ex vivo binding of ${ }^{125}$ I-7E3 to platelets removed from the dog before and after giving the $F\left(a^{\prime}\right)_{2}$ fragments (6). Plasma for the other studies was obtained from blood samples kept on ice until the end of the experiment, then centrifuged at $3,000 \mathrm{~g}$ at $22^{\circ} \mathrm{C}$ for $10 \mathrm{~min}$ and stored at $-20^{\circ} \mathrm{C}$. The assays were performed as previously described (9).

Pathologic examination. At the end of the experiment, the dogs were killed by an overdose of pentobarbital. Thrombosed stenotic and poststenotic segments of the left anterior descending coronary artery of three dogs given rt-PA alone were removed intact and fixed overnight in $5 \%$ formaldehyde. The segments were sectioned at 2-mm intervals, stained with hematoxylin and eosin and evaluated microscopically. Five dogs receiving antiplatelet antibody were subjected to perfusion fixation and scanning electron microscopy of the left anterior descending coronary artery. The artery segment was prepared as previously described (10).

\section{Results}

Dogs treated with rt-PA alone. 10 animals were studied. Two of these were excluded from analysis; one failed to achieve reperfusion despite $60 \mathrm{~min}$ of rt-PA and the second died immediately after reperfusion due to ventricular fibrillation. In the remaining eight dogs (Table I), the permanent constriction reduced the blood flow to $38 \pm 10 \%$ of the baseline value before thrombus formation. The time to reperfusion after the start of the rt-PA infusion was $23 \pm 7$ min (mean \pm SD). No significant differences were observed between the groups receiving the two different forms of rt-PA at the different infusion rates. This finding is consistent with the observation that the specific thrombolytic activity of the predominantly two-chain preparation of rt-PA (G11021) is somewhat greater than that of the predominantly one-chain form (G11035) (11). After reperfusion, seven of the eight dogs rethrombosed rapidly with a mean time to reocclusion of $7 \pm 5 \mathrm{~min}$. In some of these animals, followed for a period of time after reocclusion, cyclic reperfusion and reocclusion occurred until either the experiment was terminated or persistent reocclusion occurred.

Dogs treated with rt-PA and $7 E 3 F\left(a b^{\prime}\right)_{2}$ fragments. 13 dogs received $\mathrm{F}\left(\mathrm{ab}^{\prime}\right)_{2}$ fragments of 7E3 at a dose of $0.7-0.8$ $\mathrm{mg} / \mathrm{kg}$ in combination with either $15 \mu \mathrm{g} / \mathrm{kg}$ per min of twochain rt-PA or $30 \mu \mathrm{g} / \mathrm{kg}$ per min of one chain rt-PA. Three dogs were excluded from analysis; two achieved spontaneous reperfusion of the coronary artery during the 10-min interval between the injection of the antibody and the scheduled start 
Table I. Results of Coronary Artery Reperfusion and Reocclusion in Dogs Given rt-PA Alone or Combined with $7 E 3-F\left(a b^{\prime}\right) 2$

\begin{tabular}{|c|c|c|c|c|c|}
\hline rt-PA batch & $\begin{array}{l}\text { Sequence } \\
\text { number }\end{array}$ & $\begin{array}{l}\text { Poststenosis } \\
\text { flow }\end{array}$ & Dose & $\begin{array}{c}\text { Reperfusion } \\
\text { time }\end{array}$ & $\begin{array}{l}\text { Reocclusion } \\
\text { time }\end{array}$ \\
\hline & & $\%$ control & $\mu g / k g$ per min $\times$ min & $\min$ & $\min$ \\
\hline \multirow[t]{3}{*}{ G11021 } & 1 & 48 & $15 \times 30$ & 33 & 11 \\
\hline & 2 & 43 & $15 \times 30$ & 22 & 5 \\
\hline & 3 & 17 & $15 \times 30$ & 34 & 15 \\
\hline \multirow{4}{*}{ G11035 } & 2 & 50 & $30 \times 30$ & 26 & $>120^{*}$ \\
\hline & 3 & 40 & $30 \times 30$ & 15 & 4 \\
\hline & 4 & 35 & $30 \times 30$ & 17 & 1 \\
\hline & 5 & 40 & $30 \times 30$ & 13 & 2 \\
\hline Total & 8 & $38 \pm 10$ & - & $23 \pm 7$ & $7 \pm 5$ \\
\hline G11021 & 4 & 33 & $15 \times 30$ & 5 & $>120$ \\
\hline \multirow[t]{6}{*}{ G11035 } & 1 & 36 & $30 \times 30$ & 8 & $>120$ \\
\hline & 2 & 45 & $30 \times 30$ & 36 & $>120$ \\
\hline & 3 & 32 & $30 \times 30$ & 9 & $>120$ \\
\hline & 4 & 37 & $30 \times 30$ & 29 & $>120$ \\
\hline & 5 & 21 & $30 \times 30$ & 17 & $>116$ \\
\hline & 6 & 36 & $30 \times 30$ & 15 & $>120$ \\
\hline Total & 10 & $37 \pm 11$ & - & $14 \pm 10$ & $>112$ \\
\hline
\end{tabular}

The data represent mean \pm SD. * Not included in the calculation of the mean value $\pm S D$.

of rt-PA; the third failed to achieve reperfusion by angiographic criteria despite $60 \mathrm{~min}$ of rt-PA.

The left anterior descending coronary artery blood flow in the remaining 10 dogs (Table $I B$ ) was decreased to an average of $37 \pm 11$ percent of the control value by the permanent constrictor. Reperfusion occurred after $14 \pm 10 \mathrm{~min}$ in this group. None of these animals had coronary reocclusion during an observation period of $\sim 2 \mathrm{~h}$.

Five of the six dogs treated with antibody prepared as previously described (6) sustained a transient decrease in blood pressure that responded to saline infusion. In contrast, none of the five dogs treated with the antibody prepared by the method described in this paper became hypotensive, suggesting that the original responses were due to a contaminating vasoactive agent, perhaps endotoxin.

Two additional dogs were injected with $0.8 \mathrm{mg} / \mathrm{kg}$ of the $\mathrm{F}\left(\mathrm{ab}^{\prime}\right)_{2}$ fragment of a control monoclonal antibody, OC-125, and then infused with $30 \mu \mathrm{g} / \mathrm{kg}$ per min of single-chain rt-PA for $60 \mathrm{~min}$. Reperfusion occurred after 36 and $60 \mathrm{~min}$ and then reocclusion was documented after another 29 and $1 \mathrm{~min}$, respectively.

Dogs treated with rt-PA and aspirin or rt-PA and dipyridamole. Four dogs were infused with $15 \mu \mathrm{g} / \mathrm{kg}$ per min of twochain rt-PA (G11021) for 30 or $60 \mathrm{~min}$ and given intravenous aspirin $(35 \mathrm{mg} / \mathrm{kg}$ ) at the time of reperfusion (Table II). Two of the dogs suffered reocclusion rapidly ( 8 and $15 \mathrm{~min}$ ), one reoccluded at $116 \mathrm{~min}$, and one remained open for $>120 \mathrm{~min}$. Three additional dogs were given aspirin $10 \mathrm{~min}$ before the start of the infusion of $30 \mu \mathrm{g} / \mathrm{kg}$ per min of single chain rt-PA
(G1 1035). All three dogs reoccluded, within 3, 10, and $6 \mathrm{~min}$, respectively.

Six dogs were treated with dipyridamole and two chain rt-PA (Table II). The coronary arteries of five of these dogs reoccluded within $11 \mathrm{~min}$, whereas one remained open for 34 min and one remained patent throughout the experiment (> $55 \mathrm{~min}$ ).

Analyses of hemostasis and platelet function. Platelet aggregation studies performed on blood obtained before and 30 min after antibody infusion showed essentially complete abolition of aggregation in response to ADP $(9 \mu \mathrm{M})$, but the shape-change response remained intact. In all of three dogs tested after aspirin injection and reperfusion with rt-PA G11035, reocclusion occurred rapidly despite abolition of the second wave of ADP-induced platelet aggregation in blood taken $30 \mathrm{~min}$ after the aspirin injection.

Platelet counts were obtained before and at the end of the experiment in seven animals treated with the $7 \mathrm{E} 3-\mathrm{F}\left(\mathrm{ab}^{\prime}\right)_{2}$. There was a mean reduction in platelet count of $18 \%$ (range $3-33 \%$ ) similar to that observed in our previous study (6).

Bleeding times were obtained in five dogs before and 20 min after 7E3-F $\left(\mathrm{ab}^{\prime}\right)_{2}$ infusion. The values before the antibody averaged 3.6 $\pm 2.6 \mathrm{~min}$ (range $1.5-5 \mathrm{~min}$ ). After antibody infusion, one bleeding time was prolonged to $15 \mathrm{~min}$, whereas the other four were increased to $>30 \mathrm{~min}$. In contrast, the bleeding time after treatment with the control monoclonal antibody in two dogs did not increase significantly (from 2 and $1.5 \mathrm{~min}$ preinfusion to 2.5 and $5.5 \mathrm{~min}$ postinfusion). In the three dogs with aspirin injection prior to the start of the rt-PA infusion, 
Table II. Results of Coronary Artery Reperfusion and Reocclusion in Dogs Given rt-PA and Acetyl Salicylic Acid (ASA) or rt-PA and Dipyridamole (DIP)

\begin{tabular}{|c|c|c|c|c|c|}
\hline rt-PA batch & $\begin{array}{c}\text { Sequence } \\
\text { number }\end{array}$ & $\begin{array}{l}\text { Poststenosis } \\
\text { flow }\end{array}$ & Dose & $\begin{array}{l}\text { Reperfusion } \\
\text { time }\end{array}$ & $\begin{array}{l}\text { Reocclusion } \\
\text { time }\end{array}$ \\
\hline & & \% control & $\mu g / \mathrm{kg} / \min \times \min$ & $\min$ & $\min$ \\
\hline \multirow[t]{2}{*}{ G11021 } & 1 & 40 & $15 \times 30$ & 44 & 116 \\
\hline & 2 & 30 & $15 \times 60$ & 41 & $>120^{*}$ \\
\hline \multirow[t]{3}{*}{ G11035 } & 1 & 48 & $30 \times 30$ & 21 & 3 \\
\hline & 2 & 50 & $30 \times 64$ & 64 & 10 \\
\hline & 3 & 37 & $30 \times 30$ & 26 & 6 \\
\hline Total & 7 & $41 \pm 8$ & - & $40 \pm 15$ & $26 \pm 44$ \\
\hline \multicolumn{6}{|c|}{ B rt-PA and DIP } \\
\hline \multirow{2}{*}{ G11021 } & 5 & 39 & $15 \times 30$ & 24 & 34 \\
\hline & 6 & 55 & $15 \times 30$ & 9 & 7 \\
\hline Total & 6 & $52 \pm 12$ & - & $12 \pm 6$ & $14 \pm 11$ \\
\hline
\end{tabular}

The data represent mean \pm SD. ${ }^{*}$ Not included in the calculation of the mean value $\pm S D$.

the bleeding time prolonged from 2.5 to $>30 \mathrm{~min}$, from 5.0 to $>30 \mathrm{~min}$ and from 2.5 to $10 \mathrm{~min}$ between the control value and the end of the experiment.

${ }^{125} \mathrm{I}-7 \mathrm{E} 3$ antibody binding studies on blood obtained before and $2 \mathrm{~h}$ after $7 \mathrm{E} 3-\mathrm{F}\left(\mathrm{ab}^{\prime}\right)_{2}$ infusion were performed on six dogs. The binding decreased by $80 \pm 4 \%$ (mean $\pm \mathrm{SD}$ ) after infusion, indicating that this percentage of GPIIb/IIIa sites was blocked by the $\mathrm{F}\left(\mathrm{ab}^{\prime}\right)_{2}$ fragments in vivo. Despite this evidence of profound inhibition of ex vivo platelet function and in vivo prolongation of the bleeding time, none of the dogs demonstrated clear evidence of excessive hemorrhage from their extensive operative wounds during the combined infusion of rt-PA and $7 \mathrm{E} 3-\mathrm{F}\left(\mathrm{ab}^{\prime}\right)_{2}$, although oozing appeared to be more pronounced with the combination than with rt-PA alone.

The rt-PA infusions did not produce significant systemic activation of the fibrinolytic system. Residual fibrinogen levels measured towards the end of the infusion of $30 \mu \mathrm{g} / \mathrm{kg}$ per min of single chain rt-PA were $92 \pm 19 \%$ (mean $\pm \mathrm{SD}, n=5$ ) of the baseline value.

Pathological findings. Histologic examination of the reoccluded vessels of dogs treated with rt-PA alone showed that the occlusion was due to platelet-rich thrombus formation. In contrast, intraluminal thrombus was absent in animals treated with both rt-PA and antibody. Scanning electron microscopy revealed extensive intimal disruption of the prestenotic segment, including the presence of circumferentially oriented tears (Fig. 1 $A$ ) and the deposition of a layer of platelets on the injured de-endothelialized surface (Fig. $1 B$ ). Small aggregates of red cells were occasionally present on the luminal surface (Fig. $1 \mathrm{~B}$ ). In the stenotic region, islands of intact endothelium were surrounded by platelet-covered areas where the endothelial cells were denuded (Fig. $1 \mathrm{C}$ ).

\section{Discussion}

Early reperfusion of thrombosed coronary arteries with thrombolytic agents may salvage ischemic areas of myocardium in patients with acute myocardial infarction, provided sustained recanalization is obtained. Available studies, however, indicate that reocclusion occurs in $\sim 25 \%$ of reperfused vessels, especially when the residual stenosis is very pronounced $(1-3)$. The canine model used in the present study was designed to simulate the occurrence of an acute, occlusive thrombus in a coronary artery, superimposed on high grade $(>90 \%)$ stenosis and endothelial injury. A fixed, high-grade stenosis was produced by a permanent constrictor, endothelial damage was induced by external trauma and an occlusive thrombus was formed just proximal to the site of stenosis. Under these circumstances, the dogs respond in a manner that closely approximates the human response, namely, clot lysis and reperfusion induced by rt-PA infusions at thrombolytic doses, consistently followed by rapid reocclusion despite full heparinization (2).

Because the reoccluding thrombi are rich in platelets, and since both heparin and a standard thrombolytic dose of rt-PA failed to prevent rethrombosis, we tested the efficacy in preventing reocclusion of a new antiplatelet agent, a murine monoclonal antibody to the platelet GPIIb/IIIa receptor that blocks the binding of fibrinogen to platelets (5-7). Whereas platelet aggregation induced by the agonists thought to operate in vivo (e.g., ADP, epinephrine, thrombin, collagen, thromboxane $\mathrm{A}_{2}$ ) is absolutely dependent upon the binding of fibrinogen (and/or perhaps fibronectin and von Willebrand factor) to this receptor (12), the antibody is capable of completely blocking platelet aggregation induced by these agonists. We chose to use the $\mathrm{F}\left(\mathrm{ab}^{\prime}\right)_{2}$ fragment rather than the intact anti- 


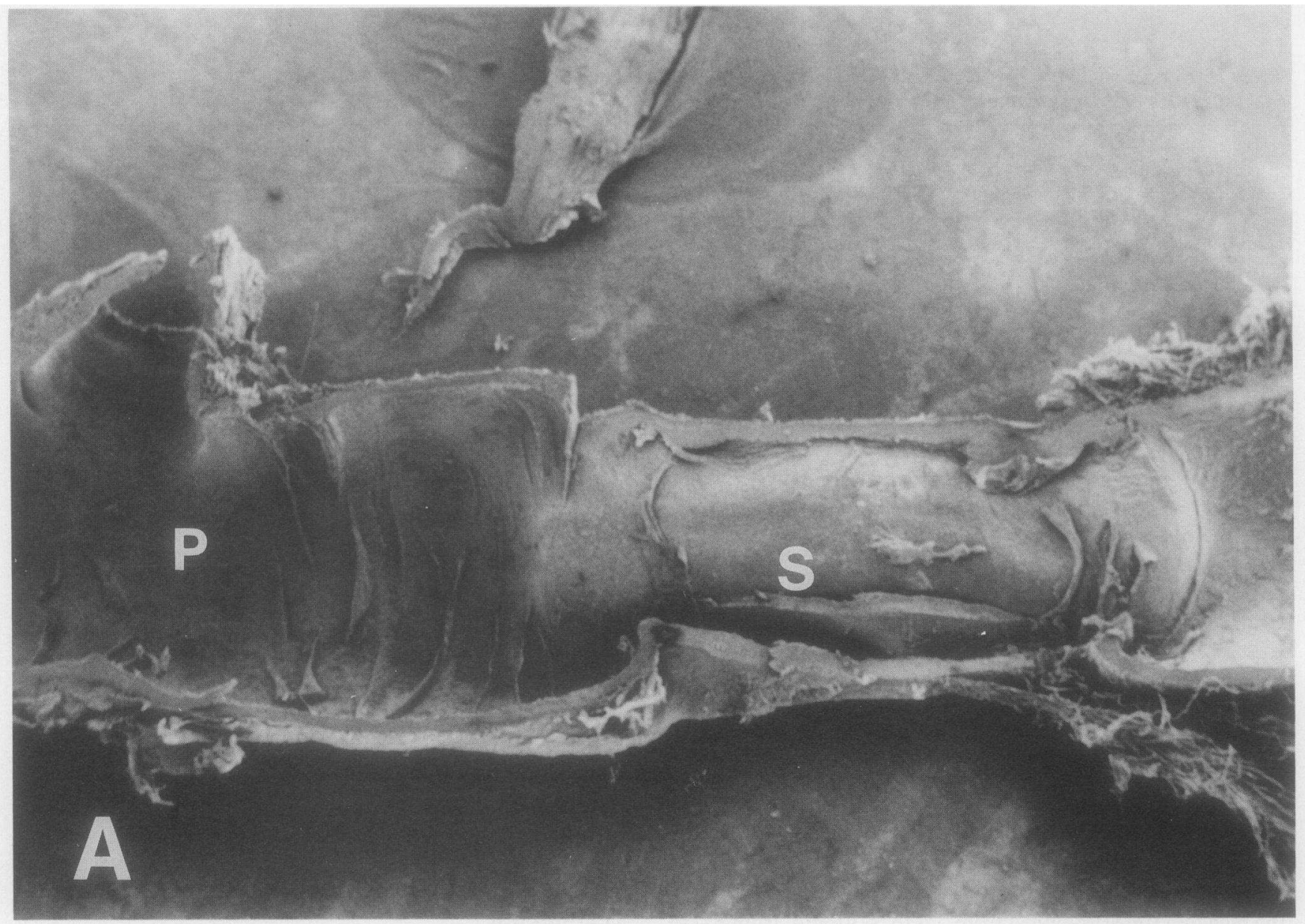

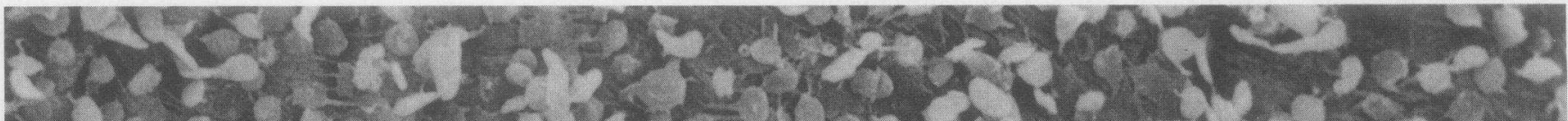

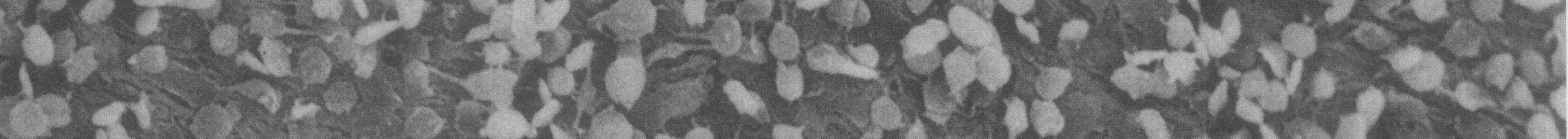

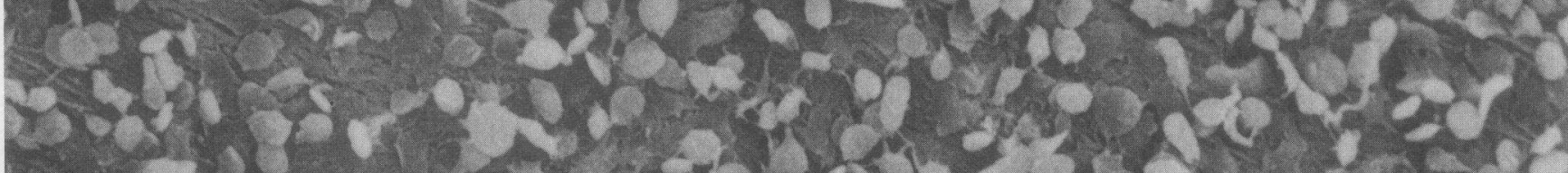

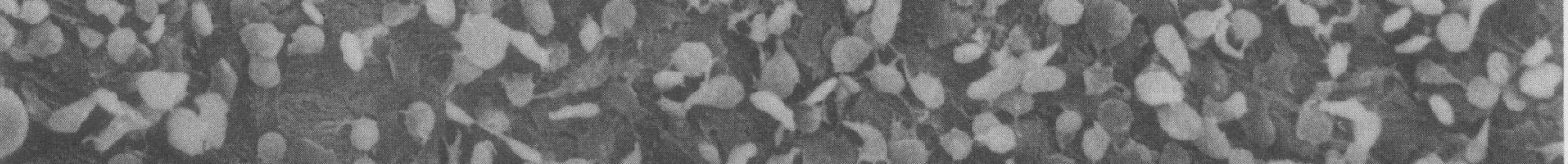

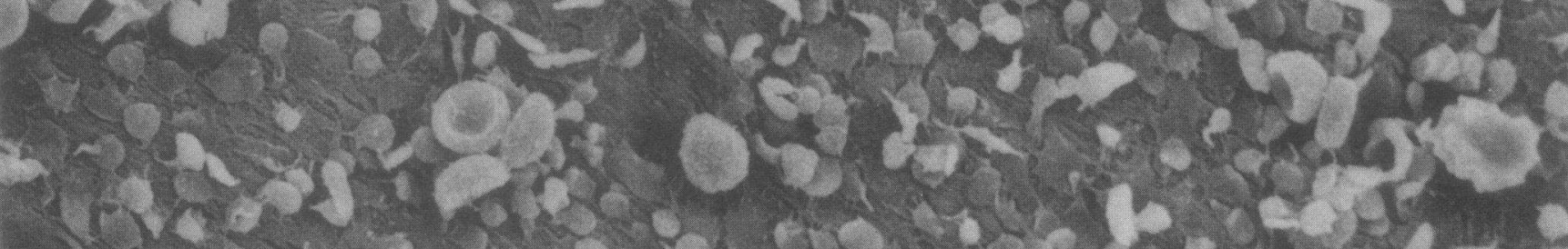

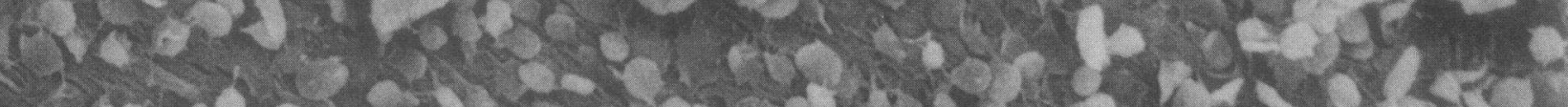

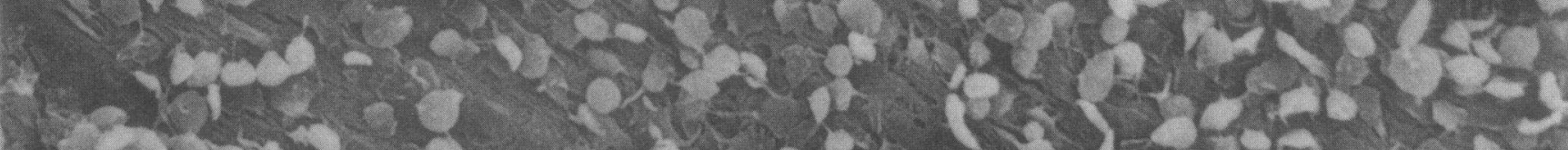

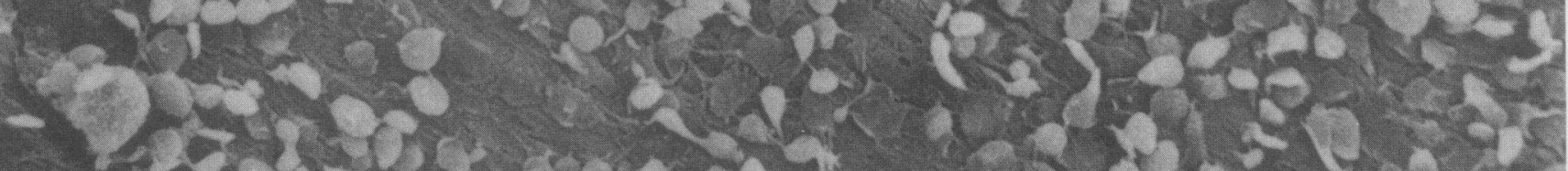

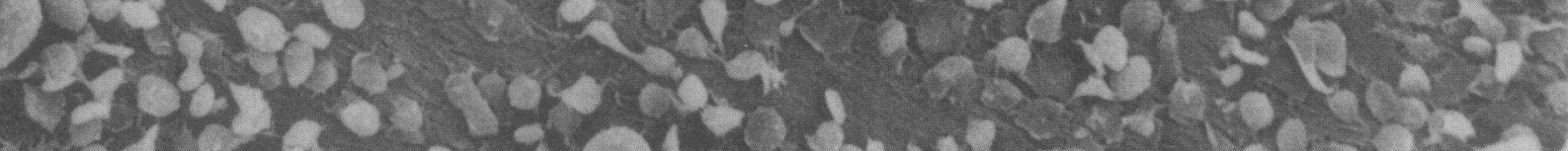

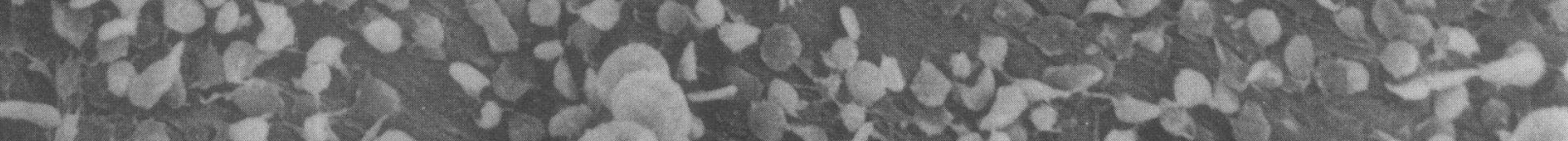

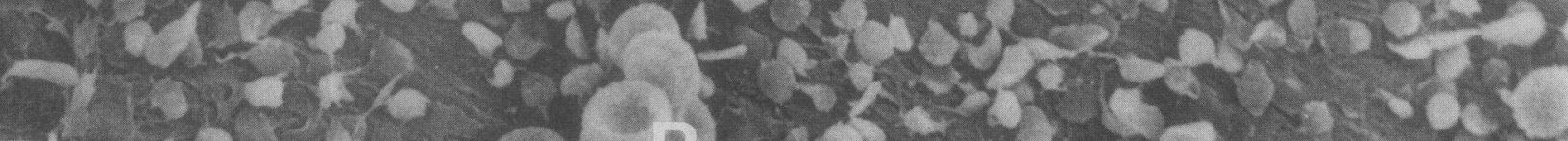

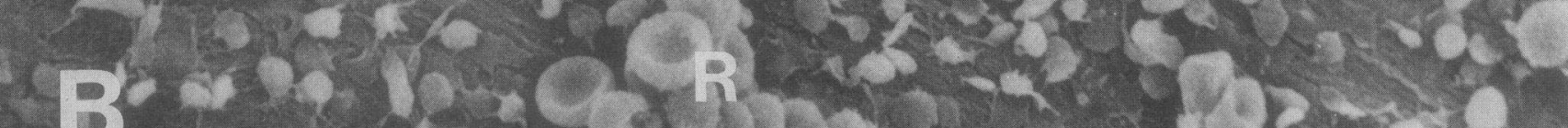

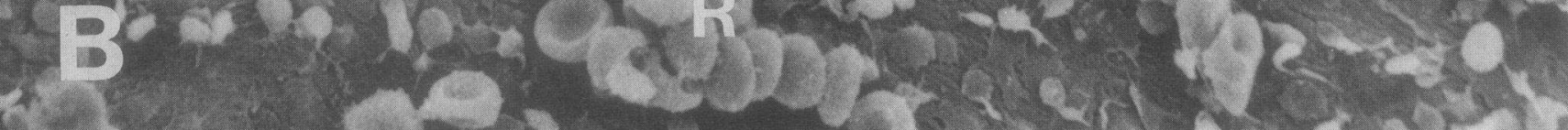

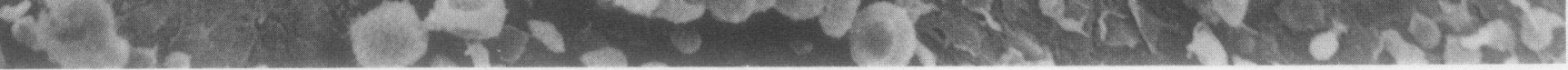




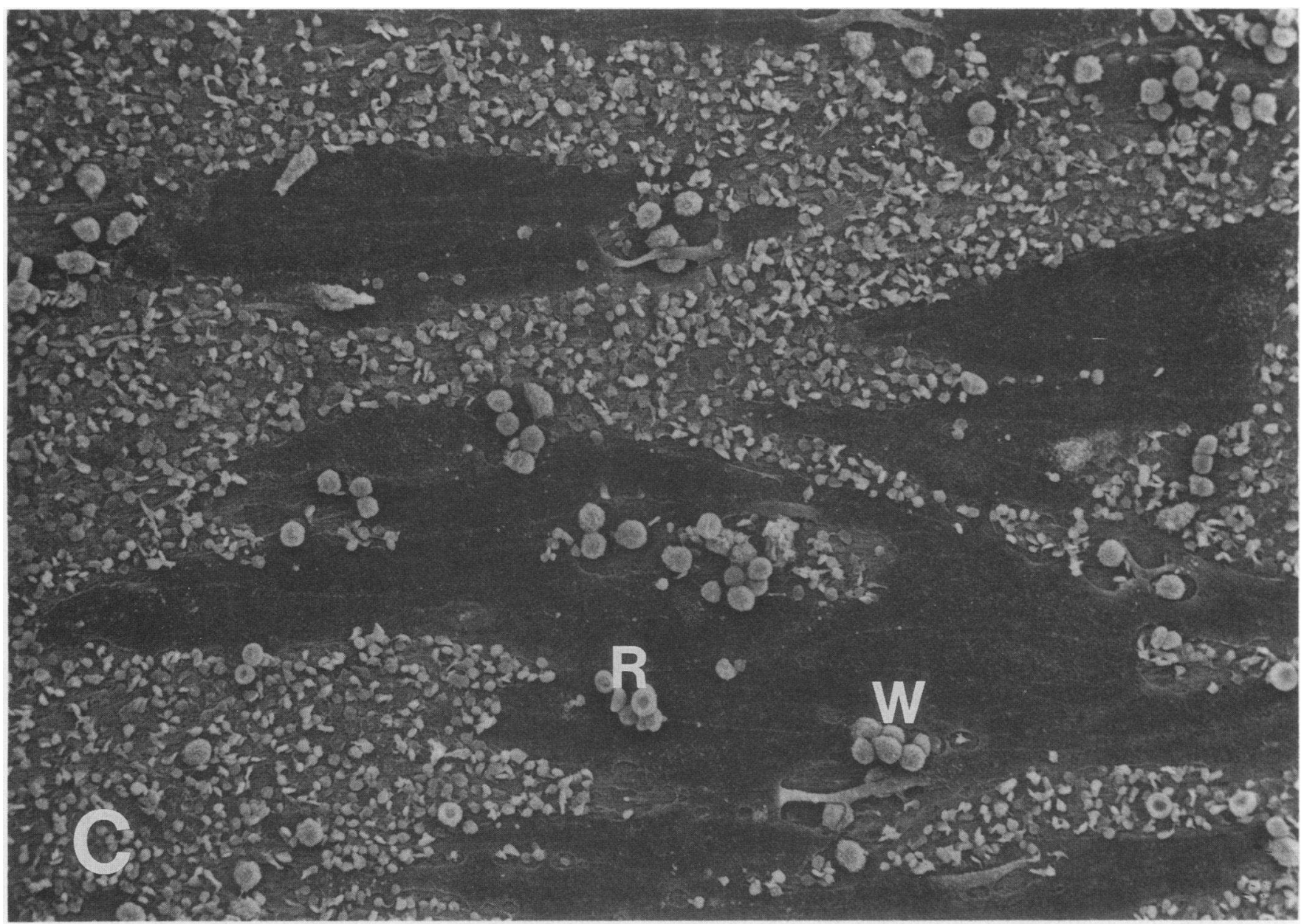

Figure 1. Scanning electron micrographs of the left anterior descending coronary artery after treatment with rt-PA and platelet antibody. (A) Low magnification micrographs reveal extensive intimal disruption with circumferentially oriented tears in the segment proximal to the stenosis $(P)$. The intimal surface of the stenotic region (S) appears relatively smooth in comparison $(\times 25)$. $(B)$ Prestenotic segment showing deposition of a layer of metamorphisizing platelets and

body so as to avoid the potential removal of antibody-coated platelets via recognition of the Fc portion of the immunoglobulin molecule.

The present study shows that the $7 \mathrm{E} 3 \mathrm{~F}\left(\mathrm{ab}^{\prime}\right)_{2}$ fragment given at a dose $(0.8 \mathrm{mg} / \mathrm{kg})$ that inhibits ADP-induced aggregation ex vivo $(6,7)$ is efficacious in preventing reocclusion after successful reperfusion with rt-PA. Indeed, the coronary arteries of all 10 reperfused dogs remained patent, whereas 7 of 8 animals treated with rt-PA alone suffered reocclusion of their coronary arteries within $30 \mathrm{~min}$. Although some of the dogs treated with the antibody that was prepared as previously described $(6,7)$ sustained transient, fluid-responsive, hypotension, this side effect was eliminated by using an alternative technique for the preparation of the antibody.

Aspirin was only partially effective in preventing reocclusion (5/7 dogs reoccluded rapidly) even though the dose employed ( $35 \mathrm{mg} / \mathrm{kg}$ ) abolished the second wave of ADP-induced platelet aggregation and prolonged the bleeding time. The ineffectiveness of aspirin may appear paradoxical given its efficacy in abolishing platelet thrombus formation in the model developed by Folts (13). Several features, however, distinguish our small aggregates of red cells $(R)$ on the deendothelialized intimal surface. Note the absence of any fibrin deposits $(\times 2,000)$. (C) Stenotic region showing islands of intact endothelium surrounded by platelet-covered areas denuded of endothelial cells. Occasional leukocytes $(\mathrm{L})$ and red cells $(\mathrm{R})$ are present on the luminal surface as well but fibrin deposits are absent $(\times 800)$.

model from the Folts model. The degree of stenosis in our model is much greater ( $>90 \%$ vs. $\sim 70 \%$ ) as demonstrated by the marked reduction in blood flow and the lack of such a decrease in the Folts model; in fact, in a study using a nonthrombotic variation of the Folts model involving a level of stenosis comparable to that used in the current study, aspirin failed to inhibit thrombus formation (14). One explanation for the inefficacy of aspirin may be its lack of effect on platelet aggregation induced by shear forces (15). In our model a fully occluding thrombin-induced thrombus is formed and then lysed, raising the possibility that residual thrombin or other platelet activating agents (ADP, thromboxane $A_{2}$, etc.) may be present in the local environment and provide a greater thrombogenic stimulus. Because the dog's coronary artery is fully occluded for $30 \mathrm{~min}$ in our model, the degree of cardiac ischemia is much greater and this may result in release of catecholamines; the latter have been shown to reverse the inhibitory effect of aspirin in the Folts model (7).

Dipyridamole was also of only minimal benefit in preventing reocclusion in this model, despite using the maximal dose $(0.6 \mathrm{mg} / \mathrm{kg})$ that can be administered without hemodynamic 
compromise. The lack of effect is not surprising given the recent evidence calling into question the efficacy of dipyridamole as an antithrombotic agent, either alone or in combination with aspirin. In particular $(a)$ recent results of several large scale clinical trials which have indicated that aspirin alone is equi-potent to combinations with dipyridamole for the prevention of arterial occlusion in patients with established cardiovascular disease (16) and $(b)$ two recent animal studies showed that dipyridamole alone had no effect and that its combination with aspirin was no more effective than aspirin alone at a dosage $>2 \mathrm{mg} / \mathrm{kg}$ in preventing platelet thrombus formation on partially stenosed dog coronary arteries $(17,18)$.

The two models with moderate and severe coronary artery stenosis may have complementary features rendering them more appropriate for different applications. The model with less severe stenosis $(14,19)$ may be more adapted to the investigation of pharmacological agents suitable for the prevention of arterial occlusion in patients with atherosclerotic disease, where aspirin has indeed been shown to be effective. The model used in the present study may be more suitable for the investigation of therapeutic approaches for the prevention of acute coronary artery reocclusion in patients with myocardial infarct, where a high grade residual stenosis after successful reperfusion with thrombolytic agents persists. In this condition the anatomical substrate consists of plaque hemorrhage, mural thrombus, endothelial damage, and fixed atherosclerotic narrowing, which in concert constitute an intense thrombogenic stimulus.

We were concerned about the potential hemorrhagic effect of the combination of agents used in this study, since the animals were subjected to extensive surgery with open operative wounds, and the agents employed [rt-PA, heparin, and $\left.7 \mathrm{E} 3-\mathrm{F}(\mathrm{ab})_{2}\right)_{2}$ inhibit all phases of hemostasis. We therefore anticipated that the addition of the monoclonal antiplatelet antibody to the heparin/rt-PA combination might provoke excessive hemorrhage, especially since the antibody produced a dramatic increase in the bleeding time. Several factors, however, may have contributed to the relative absence of excessive hemorrhage during the combined infusion of rt-PA and 7E3 $\mathrm{F}\left(\mathrm{ab}^{\prime}\right)_{2}$. Firstly, most of the invasive procedures were completed before the agents were administered, thus possibly permitting hemostatic plugs to mature. Moreover, the antibody only blocks the receptor-mediating platelet aggregate formation, leaving intact other platelet receptors for collagen, von Willebrand factor, and perhaps fibronectin, that probably are more important in mediating adhesion of platelets to the subendothelium $(13,14,20)$. In support of this hypothesis, similar antibodies have had a more dramatic effect on platelet aggregation than on platelet adhesion in model systems (20-22). In addition, platelets treated with a similar antibody also retained the ability to undergo the release reaction and facilitate fibrin formation (22). Finally, although prolongation of the bleeding time must be considered a significant risk factor for excessive hemorrhage, patients who have long bleeding times because they are congenitally deficient in the GPIIb/IIIa receptor (Glanzmann thrombasthenia) usually only bleed excessively with trauma or other provocations (23), and patients with long bleeding times as a result of treatment with the drug ticlopidine, which interferes with the GPIIb/IIIa receptor by an unknown mechanism, appear to be at low risk for spontaneous hemorrhage $(24,25)$. There is thus reason to hope that with the antiplatelet antibody it may be possible to completely inhibit platelet aggregation, the process most likely to produce vasoocclusion, without significantly inhibiting platelet adhesion and other platelet functions that contribute to maintaining hemostasis. The potential hemorrhagic risk of short term therapy with the combination of $7 \mathrm{E} 3 \mathrm{~F}\left(\mathrm{ab}^{\prime}\right)_{2}$, with a rapidly cleared thrombolytic agent such as rt-PA and a rapidly reversible anticoagulant, thus may be justified if the combination is found to be highly effective in treating this life-threatening illness.

In conclusion, the present study indicates that infusion of $\mathrm{F}\left(\mathrm{ab}^{\prime}\right)_{2}$ fragments of monoclonal antibody $7 \mathrm{E} 3$, which is directed against the platelet GPIIb/IIIa receptor, can efficiently protect against coronary artery reocclusion that follows thrombolysis with rt-PA, despite the presence of high-grade residual stenosis. Whether such treatment can be administered safely to humans or has value as an alternative to maintenance rt-PA infusion remains to be further investigated.

\section{Acknowledgments}

We want to thank Missy Stanton and Shirley Murray for outstanding secretarial support.

Supported in part by grant HL-26215 (Ischemic Specialized Center of Research), HL-35058 (Thrombosis Specialized Center of Research), and 19278 from the National Heart, Lung, and Blood Institute.

\section{References}

1. Collen, D., E. J. Topol, A. J. Tiefenbrunn, H. K. Gold, M. L. Weisfeldt, B. E. Sobel, R. C. Leinbach, J. A. Brinker, T. Yasuda, B. H. Bulkley, A. K. Robison, A. M. Hutter, Jr., W. R. Bell, J. J. Spadaro, Jr., B. A. Khaw, and E. B. Grossbard. 1984. Coronary thrombolysis with recombinant human tissue-type plasminogen activator. A prospective, randomized, placebo-controlled trial. Circulation. 70:1012-1017.

2. Gold, H. K., R. C. Leinbach, H. D. Garabedian, T. Yasuda, J. A. Johns, E. B. Grossbard, L. Palacios, and D. Collen. 1986. Acute coronary reocclusion after thrombolysis with recombinant human tissuetype plasminogen activator. Prevention by a maintenance infusion. Circulation. 73:347-352.

3. Harrison, D. G., D. W. Ferguson, S. M. Collins, D. J. Skorton, E. E. Ericksen, J. M. Kioschos, M. L. Marcus, and C. W. White. 1984. Rethrombosis after reperfusion with streptokinase: Importance of geometry of residual lesions. Circulation. 69:991-998.

4. Davies, M. J., and A. C. Thomas. 1985. Plaque fissuring-the cause of acute myocardial infarction, sudden ischemic death, and crescendo angina. Br. Heart J. 53:363-373.

5. Coller, B. S. 1985. A new murine monoclonal antibody reports an activation-dependent change in the conformation and/or microenvironment of the platelet GPIIb/IIIa complex. J. Clin. Invest. 76:101103.

6. Coller, B. S., and L. E. Scudder. 1986. Inhibition of dog platelet function by in vivo infusion of $F\left(a^{\prime}\right) 2$ fragments of a monoclonal antibody. Blood. 66:1456-1459.

7. Coller, B. S., J. D. Folts, L. E. Scudder, and S. R. Smith. 1986. Antithrombotic effect of a monoclonal antibody to the platelet glycoprotein IIb/IIIa receptor in an experimental animal model. Blood. 68:783-786.

8. Bast, R. C., M. E. Feeney, H. Lazarus, L. M. Nadler, R. B. Coldin, and R. C. Knapp. 1981. Reactivity of a monoclonal antibody with human ovarian carcinoma. J. Clin. Invest. 68:1331-1337.

9. Gold, H. K., J. Fallon, T. Yasuda, R. C. Leinbach, B. A. Khaw, J. B. Newell, J. L. Guerrero, F. M. Vislosky, C. F. Hoyng, E. Grossbard, and D. Collen. 1984. Coronary thrombolysis with recombinant human tissue-type plasminogen activator. Circulation. 70:700-707.

10. O’Gara, P. T., J. L. Guerrero, B. Feldman, J. T. Fallon, P. C. 
Block. 1984. Effect of dextran and aspirin on platelet adherence after transluminal angioplasty of normal canine coronary arteries. Am. J. Cardiol. 53:1695-1698.

11. Garabedian, H. A., H. K. Gold, R. C. Leinbach, J. A. Johns, T. Yasuda, M. Kanke, and D. Collen. 1987. Comparative properties of two clinical preparations of recombinant human tissue-type plasminogen activator in patients with acute myocardial infarction. J. Am. Coll. Cardiol. 9:599-607.

12. Coller, B. S. 1986. Blood elements at surfaces: Platelets. Ann. NY Acad. Sci. In press.

13. Folts, J. D., E. B. Crowell, and F. F. Rowe. 1976. Platelet aggregation in partially obstructed vessels and its elimination with aspirin. Circulation. 54:365-370.

14. Aiken, J. W., R. J. Shebuski, O. V. Miller, and R. R. Graham. 1981. Endogenous prostacyclin contributes to the efficacy of a thromboxane synthetase inhibitor for preventing coronary artery thrombosis. J. Pharmacol. Exp. Ther. 219:299-308.

15. Stevens, D. E., J. H. Joist, and S. P. Sutera. 1980. Role of platelet prostaglandin synthesis in shear-induced platelet alterations. Blood. 56:753-758.

16. Harker, L. A., and V. Fuster. 1986. Pharmacology of platelet inhibitors. J. Am. Coll. Cardiol. 8:21B-32B.

17. Weselcouch, E. O., W. R. Humphrey, and J. W. Aiken. 1987. Effects of low doses of aspirin and dipyridamole on platelet aggregation in the dog coronary artery. J. Pharmacol. Exp. Ther. 240:37-43.

18. Folts, J. D., and S. R. Smith. 1987. Dipyridamole alone or with low dose aspirin does not prevent acute platelet thrombus formation in stenosed dog coronary arteries. Thromb. Haemostasis. 58:210. (Abstr.)
19. Willerson, J. T., L. D. Hillis, M. Winniford, and L. M. Buja. 1986. Speculation regarding mechanisms responsible for acute ischemic heart disease syndromes. J. Am. Coll. Cardiol. 8:245-250.

20. Eldor, A., I. Vlocavsky, U. Martinowicz, A. Fuks, and B. S. Coller. 1985. Platelet-fibrinogen interactions are essential for platelet aggregation but not for the matrix-induced release reaction. Blood. 65:1477-1483.

21. Sakariassen, K. S., P. F. E. M. Nievelstein, B. S. Coller, and J. J. Sixma. 1986. The role of platelet membrane glycoproteins $\mathrm{Ib}$ and IIb-IIIa in platelet adherence to human artery subendothelium. $\mathrm{Br}$. $J$. Haematol. 63:681-691.

22. Coller, B. S., E. I. Peerschke, L. E. Scudder, and C. A. Sullivan. 1983. A murine monoclonal antibody that completely blocks the binding of fibrinogen to platelets produces a thrombasthenic-like state in normal platelets and binds to glycoproteins IIb and/or IIIa. J. Clin. Invest. 72:325-338.

23. Seligsohn, U., and S. Roshoshansky. 1984. A Glanzmann's thrombasthenia cluster among Iraqi Jews in Israel. Thromb. Haemostasis. 52:230-231.

24. DiMinno, G., A. M. Lerbone, P. L. Mattiol, S. Turco, C. Iovine, and M. Mancini. 1985. Functionally thrombasthenic state in normal platelets following administration of ticlopidine. J. Clin. Invest. $75: 320-338$.

25. Conrad, J., C. Lecrubier, P. Y. Scarabin, M. H. Horellou, M. Samama, and M. G. Bousser. 1980. Effects of long term administration of ticlopidine on platelet function and hemostatic variables. Thromb. Res. 20:143-148. 